via pelo menos uns dez potenciais candidatos, vários deles ansiosos por essa posição, não só pelo poder, mas também pelo adicional agregado aos vencimentos, que pode ser incorporado à aposentadoria.

JOSÉ DE SOUZA MARTINS é sociólogo, professor emérito da Faculdade de Filosofia, Letras e Ciências Humanas da Universidade de São Paulo; fellow de Trinity Hall e Simon Bolivar Professor da Universidade de Cambridge (1993-1994); professor honoris causa da Universidade Federal de Viçosa, MG (2013); doutor honoris causa pela Universidade Federal da Paraíba (2013). E-mail: jose38@uol.com.br.

\section{Determinantes da descentralização}

Tulia Falleti. Decentralization and subnational politics in Latin America. Cambridge, Cambridge University Press, 2010. 285 páginas.

\section{Cecilia Viana}

Críticos e defensores da descentralização têm em comum ao menos a premissa de que a transferência de recursos, responsabilidades e autoridade resultam em maiores poderes para os governos subnacionais. Em Decentralization and subnational politics in Latin America, Tulia Falleti coloca essa afirmação à prova. Partindo de referenciais teóricos como a dependência da trajetória, a evolução institucional e os efeitos do tempo em processos políticos, a autora discute o grau de mudança no balanço de poder entre níveis do governo resultante da descentralização. Esse é o primeiro livro autoral de Falleti, cujo conjunto de publicações acadêmicas se centram em temas como descentralização, federalismo, democracia e política comparada na América Latina. Professora da Universidade da Pensilvânia e de nacionalidade argentina, Falleti recebeu prêmios por alguns de seus trabalhos, entre os quais o livro aqui resenhado.

Sua abordagem se dá a partir da teoria sequencial da descentralização. Nessa proposta metodológica, a ordem em que ocorrem os três tipos de descentralização (administrativa, fiscal e política) depende dos interesses territoriais dominantes e determina o balanço final de poder. Os casos da Argentina, da Colômbia, do Brasil e do México analisados no livro indicam que os resultados da descentralização variam, e os procedimentos metodológicos empregados na análise se mostram úteis para explicar o porquê dessa variação.

Uma das principais contribuições do livro para a literatura de descentralização é a atenção dada aos interesses territoriais dos atores. $\mathrm{Na}$ análise de Falleti, quando atores se unem em torno do nível de governo (central, intermediário ou local) que defendem, esses interesses predominam sobre coalizões partidárias. Sem restringir os participantes ao executivo dos governos, Falleti defende que os representantes do governo central irão preferir a descentralização administrativa, seguida da fiscal e 
por último a política. Essa sequência garante um poder maior ao nível mais elevado de governo sobre os subnacionais, pois transfere primeiro as responsabilidades e só depois os recursos para implementá-las, permitindo assim ao governo central manter um controle político ainda que a descentralização política venha a seguir. Já para governadores ou prefeitos, a ordem preferida é a inversa: primeiro a descentralização política, depois a fiscal e por último a administrativa. Assim, os governos locais garantem maior autonomia para governar e mais liberdade para defender suas demandas ante o governo central. Com maior poder de barganha, a reforma fiscal provavelmente virá a seguir, e só então serão transferidas as responsabilidades de provisão de serviços aos governos locais. O resultado da descentralização será fortemente influenciado pela prevalência de um ou outro grupo de atores ao longo do processo.

O conteúdo das reformas é determinado pelo comportamento estratégico e pelos interesses territoriais predominantes dos atores envolvidos na negociação, mas fatores contextuais e legados históricos podem limitar ou aumentar o alcance da descentralização. A autora parte da ideia de que o primeiro tipo de reforma adotado influencia fortemente as próximas etapas do processo, uma vez que torna uma sequência mais ou menos provável de ocorrer. Essa dependência da trajetória ocorre por a tendência de mecanismos de autoafirmação afetar as políticas, em um feedback positivo de prevalência dos interesses iniciais. No entanto, mecanismos reativos também podem ocorrer, como exemplificado pelo caso mexicano.

Do capítulo 3 ao 6, Falleti aplica a sua teoria sequencial da descentralização na análise dos casos de descentralização na Argentina, na Colômbia, no Brasil e no México. A autora apresenta fatores contextuais e institucionais e processos políticos particulares de cada contexto para analisar a sequência pela qual se deu a descentralização em cada caso. Ela se aprofunda na primeira política do setor social que passa pelo ciclo completo das três formas de descentralização: a educação na Argentina, no México e na Colômbia e a saúde no Brasil. O estudo inicia no período de reformas pós-desenvolvimentismo, ou seja, com o início de reformas neoliberais acerca de 1980 nos quatro países. Os casos selecionados são os maiores países da América Latina em termos de território, o que torna a descentralização especialmente relevante para eles; além disso, têm estruturas similares de governo, permitindo uma análise comparada. Por outro lado, os quatro países diferenciam-se em relação à autonomia preexistente dos governos subnacionais, à estrutura do sistema partidário e ao balanço de poder resultante da descentralização apresentado no segundo capítulo.

$\mathrm{Na}$ Argentina, o processo de descentralização foi impulsionado durante o regime militar com o objetivo de transferir responsabilidades sem o repasse de recursos do governo central para as províncias (equivalente aos nossos estados). Ou seja, prevaleceram os interesses do governo central de "desafogar" suas responsabilidades e diminuir o tamanho do Estado. Portanto, a primeira reforma foi a administrativa, na qual a educação primária passou às mãos das províncias. Já no período democrático, apesar de terem o seu poder de barganha reduzido pela primeira rodada de reformas, os governadores conseguiram formar uma coalizão e promover uma descentralização fiscal. No entanto, o governo central pôde controlar o momento e a extensão dessa transferência. Em um segundo momento ocorreu um retrocesso na distribuição de recursos com a descentralização das escolas secundárias. Essa sequência se deu pela mudança de interesses predominantes: na descentralização fiscal, a coalizão de governadores prevaleceu; na segunda descentralização administrativa, as coalizões partidárias foram mais fortes. Em um quarto momento, a reforma política ocorreu por interesse do governo central em usá-la na barganha pelo segundo mandato presidencial de Carlos Menem. Como resultado da predominância dos interesses do governo central e dos efeitos de mecanismos de autoafirmação dos interesses predominantes sobre as políticas, a descentralização na Argentina não mudou o balanço de poder entre níveis de governo.

O caso da Colômbia é bastante distinto. Uma série de fatores contextuais - entre os quais a mobilização da sociedade civil - resultou em uma coalizão entre governo nacional e oposiçôes locais que favoreceu a reforma política. Os prefeitos 
recém-eleitos pelo voto popular criaram uma associação que cumpriu papel importante na negociação com o governo central das reformas que se seguiram. Assim, a rodada seguinte de descentralização foi a fiscal, seguida pela administrativa, conforme a preferência dos atores subnacionais por aumentar sua autonomia e poder perante níveis mais altos de governo.

O caso brasileiro seguiu a mesma sequência, mas com o diferencial de que a reforma administrativa foi impulsionada por interesses locais. Esse fato se contrapôe às expectativas da autora de que a transferência de responsabilidades seria do interesse do governo central, e não das esferas locais. $\mathrm{O}$ que ocorreu no Brasil foi a prevalência das coalizóes subnacionais em todas as etapas da descentralização. As eleições diretas para governadores em 1982 deram início a um mecanismo de feedback positivo que aumentou a força e a autonomia dos estados e municípios, concedendo a eles um poder muito maior do que aquele experimentado nos outros países. Assim, no Brasil houve primeiro a descentralização política, depois a fiscal e por último a administrativa.

O México oferece uma outra sequência de descentralização. $\mathrm{Na}$ tentativa de se renovar e se manter no poder, a coalizão que ocupava o governo central transferiu responsabilidades aos estados, junto com os recursos necessários para a sua implementação. Praticamente ao mesmo tempo, o governo central fortaleceu politicamente os municípios ao definir as responsabilidades e os repasses do governo central, permitindo à esfera local a coleta de impostos exclusivos. A partir dessas reformas, os atores subnacionais organizaram associaçôes municipais que obtiveram elevado poder de barganha na negociação da descentralização fiscal. Diferentemente da Argentina, onde mecanismos de autoafirmaçao aumentaram o poder do governo central, no México houve um movimento reativo dos interesses subnacionais, alterando a sequência esperada de reformas.

Apesar de a proposta da teoria sequencial da descentralização constituir um método claro e útil, em alguns momentos a separação de processos para adequar os casos ao modelo teórico resultou em certa confusão. Isso se dá especialmente no caso do
México, que passou por tipos de descentralização diferentes em um curto período de tempo. Sabendo disso, a autora se vale de elementos gráficos na tentativa de elucidar sua teoria, mas eles não se mostram suficientemente claros para fazer as distinções dos processos. Apesar de o texto se tornar repetitivo em alguns momentos, a autora conseguiu relacionar com clareza os estudos de caso à teoria. Esta talvez tenha sido sua estratégia para reafirmar sua proposta teórica.

No primeiro capítulo, a autora apresenta as diferentes tentativas de explicar as origens da descentralização e defende a ideia de que as causas são variadas demais para permitir generalizaçôes. Falleti não aborda as causas da descentralização de forma mais ampla, e sim as dinâmicas políticas que levam a diferentes tipos de descentralização. No entanto, é interessante observar que todos os países analisados passaram por esse tipo de reforma em momentos semelhantes. O livro poderia ganhar com uma discussão mais aprofundada sobre as origens e os motivos da descentralização, o que não significa que o produto como um todo não seja coeso e suficiente para o que se propõe.

Falleti se baseia em informações coletadas a partir de numerosas entrevistas e trabalho de campo, pesquisa em arquivo e dados quantitativos secundários, organizadas em sua tese de doutorado da qual o livro é proveniente. A clareza e a concisão de argumentos e conceitos e a metodologia aplicada permitem uma leitura fluida, apesar de sua densidade teórica. O texto é enriquecido com elementos gráficos, e as múltiplas notas de rodapé oferecem interessantes informações complementares e anedotas sobre os temas abordados.

O rigor metodológico por si já é suficiente para tornar Decentralization and subnational politics in Latin America recomendável a interessados em ciências sociais de maneira geral. Além disso, os estudos de caso são ricos em detalhes e oferecem uma excelente contribuição para o entendimento dos processos políticos na América Latina, atraindo certamente acadêmicos da área de políticas públicas na América Latina. Para os interessados na temática de descentralização, a proposta metodológica da autora fornece elementos que podem ser aplicados em análises de casos de outras políticas, para além 
da América Latina. Para estes, o livro constitui leitura obrigatória.

CECILIA VIANA é doutoranda em desenvolvimento sustentável, Centro de Desenvolvimento Sustentável da Universidade de Brasília. E-mail: ceciliaviana@aluno.unb.br.

\section{Intervençóes urbanas e "cidades rebeldes"}

David Harvey. Rebel cities: from the right to the city to the urban revolution. Londres/Nova York, Verso, 2012. 205 páginas.

\section{Edson Alencar Collares de Bessa}

Em sua vasta produção bibliográfica recente, o geógrafo inglês e professor emérito de antropologia social na The City University of New York (Cuny), David Harvey, amplia suas reflexões acerca da atuação do capitalismo na atualidade. Em Rebel cities: from the right to the city to the urban revolution, o autor continua sua enfática crítica ao modelo capitalista de produção e as consequências dele para a vida das pessoas. Embora ressaltando pontos de vista já enfocados em outras obras, Harvey demonstra aqui a centralidade do processo de urbanização e suas escalas para o capitalismo por meio da análise de diferentes períodos e espaços onde ocorreram intervenções urbanísticas. Com essa justificativa teórica alicerçada nas ideias de outros intelectuais, principalmente Henri Lefebvre, há uma explícita manifestação de retomada dos centros urbanos ante o sistema do capital por meio de uma revolução popular, constituindo a formação de "cidades rebeldes".

Dividido em duas seçôes, o livro mostra como a urbanização se tornou mais uma faceta da produção capitalista. Na primeira seção, intitulada "The right to the city", Harvey apresenta sua perspectiva analítica ao conceber suas premissas teóricas, fortalecendo proposições de cunho histórico processual. $\mathrm{Na}$ segunda seção, "Rebel cities", o tom do livro torna-se um manifesto motivacional para a retomada das cidades pela população oprimida pelo sistema. Vale destacar que os capítulos de ambas as seções são ensaios isolados, sendo, portanto, adaptados ao livro com algumas alterações.

O elo entre as seções é a Comuna de Paris, que perpassa a obra. Harvey ressalta constantemente esse movimento social do operariado francês a fim de mostrar que ele foi central para pensar as formulações comunistas, embora tenha usado a questão urbana em Marx apenas como exemplo e não como análise principal. Por isso, Harvey expõe o 